\title{
Sistema multimídia de apoio à decisão em procedimentos de higiene para unidades de alimentação e nutrição ${ }^{1}$
}

\author{
Multimedia decision support system in hygiene \\ procedures for food facilities
}

Maria Aparecida ANTUNES²

Nélio José ANDRADE²

Carlos Arthur Barbosa SILVA²

Raquel Monteiro Cordeiro AZEREDO ${ }^{3}$

Franceline Aparecida LOPES²

\section{R E S U M O}

É objetivo deste estudo desenvolver um sistema multimídia com a finalidade de subsidiar a melhoria de procedimentos de higiene em Unidades de Alimentação e Nutrição. O sistema Clean Up, composto de várias bases de conhecimento e informações interligadas e organizadas em módulos foi avaliado por 30 usuários que responderam ao teste de aceitação baseado na Escala Likert modificada, com os atributos próprios de escala hedônica, com notas de 1 a 9, para classificação que varia de "extremamente bom" a "extremamente ruim". A partir dos dados coletados foram calculadas a moda e os valores máximo e mínimo das notas para cada atributo julgado pelos avaliadores. A nota 8 foi a mais freqüente, classificando os módulos como "muito bom", segundo a escala Likert. É também função do multimídia entreter o usuário. As cores, sons, filmes, imagens devem surpreender e criar expectativas positivas, aumentando a vontade de explorar o conteúdo durante a aquisição do conhecimento.

Termos de Indexação: higiene de alimentos; sistema multimídia; unidades de alimentação e nutrição.

\section{A B S T R A C T}

The purpose of this study was to develop a multimedia system to help improve hygiene practices in food facilities. The Clean Up system, composed of many knowledge bases and interconnected information organized

\footnotetext{
1 Artigo elaborado a partir da dissertação de M.A. ANTUNES, intitulada "Sistema multimídia de apoio a decisão em procedimentos de higiene para Unidades de Alimentação e Nutrição". Universidade Federal de Viçosa; 2003.

2 Departamento de Tecnologia de Alimentos, Universidade Federal de Viçosa. Av. P.H. Rolfs, s/n, Centro, 36570-000, Viçosa MG, Brasil. Correspondência para/Correpondence to: N.J. ANDRADE. E-mail: <nandrade@ufv.br>

3 Departamento de Nutrição e Saúde, Universidade Federal de Viçosa. Viçosa, MG, Brasil.
} 
in modules, was tested by 30 users who answered an acceptability test based on the modified Likert Scale, with typical hedonic scale attributes and grades ranging from 1 to 9, in a classification that varied from "extremely good" to "extremely bad." The mode and the maximum and minimum values of the grades given to each attribute judged by the users were calculated from the collected data. The most frequent grade given in the quantitative assessment of the modules was 8, that is, "very good" according to the Likert Scale. The multimedia should also entertain the user. Colors, sounds, films and images must surprise the user and create positive expectations, increasing the user's will to explore its contents during learning.

Indexing terms: food hygiene; multimedia system; food service unit.

\section{N T R O D U Ç Ã O}

Atualmente, existem cerca de mil empresas de refeições coletivas no Brasil que serviram, no ano de 2003, cerca de 5,2 milhões de refeições/dia, com um faturamento anual de 5 bilhões de reais ${ }^{1}$. Este é um mercado importante que gera empregos e beneficia ao trabalhador. Estas empresas, assim como outros locais que processam alimentos para consumo fora do lar, são Unidades de Alimentação e Nutrição e têm a finalidade de oferecer alimentos com boas qualidades nutricionais, sensoriais e higiênico-sanitárias. Entretanto, os alimentos preparados em UAN são responsáveis pela maioria de casos informados de doenças de origem alimentar confirmados em várias partes do Brasil e do mundo, de acordo com os dados epidemiológicos.

Uma pesquisa realizada nos Estados Unidos relacionou as principais fontes com os fatores que levaram à ocorrência de surtos de doenças de origem alimentar ${ }^{2}$. Em 65,0\% desses surtos, os alimentos foram adquiridos em restaurantes, em 17,0\% em supermercados e em $1,0 \%$ os alimen-tos eram industrializados. Alimentos consumidos em lares responderam por $17,0 \%$ dos surtos. Os principais fatores que levaram aos surtos foram, o uso de sobras e alimentos com data de validade vencida $(27,0 \%)$, resfriamento inadequado $(23,0 \%)$, alimento contaminado e de origem não segura $(12,0 \%)$, cocção inadequada (10,0\%), má-higienização e contaminação cruzada $(7,0 \%)$, reaquecimento inadequado $(1,0 \%)$ e outros fatores $(20,0 \%)$. Concluiu-se, ainda, pela pesquisa que os alimentos mais envolvidos eram carnes, aves e derivados e as doenças acometiam mais os jovens adultos com menos de 40 anos. No Japão e na Coréia, entre 1981 e 1995, a distribuição mensal e sazonal de surtos indicou que a ocorrência estava fortemente relacionada às condições climáticas, feriados nacionais e períodos de férias. Na Coréia, os surtos estavam mais ligados a preparações caseiras, envolvendo $47,0 \%$ do total de casos, e, no Japão, ligados a restaurantes, com 31,3\% ${ }^{3}$.

No Brasil, dados da Fundação Ezequiel Dias, em Minas Gerais, relatam sobre surtos ocorridos por intoxicação estafilocócica identificados em diferentes regiões do Estado, entre 1995 e 2000. Refeições prontas foram responsáveis por 52 surtos com 9500 pessoas acometidas e 16 mortes $^{4}$.

Este trabalho procurou desenvolver um meio informatizado para atualizar conhecimentos sobre os procedimentos de higiene dos profissionais responsáveis pela qualidade nas UAN, por intermédio de recursos multimídia, com interface amigável para motivação do usuário.

O objetivo final é proporcionar uma ferramenta para melhoria dos procedimentos de higienização para que sejam alcançados índices microbiológicos compatíveis com as recomendações da American Public Health Association $(\mathrm{APHA})^{5}$ e pela Resolução de Diretoria Colegiada n¹2 da Anvisa/2001 (Brasil, 2001), referentes aos equipamentos e utensílios, manipuladores de alimentos, ar de ambientes de processamento e alimentos processados, dentre outros vigentes $^{5,6-12}$.

\section{MÉTODOS}

O desenvolvimento do sistema multimídia de apoio à decisão foi iniciado por uma fase de obtenção de informações, em que se adquiriram conhecimentos acerca de: 
a) Qualidade e controle da água para Unidades de Alimentação e Nutrição. Foram adquiridas informações sobre i) legislação brasileira; ii) padrões de potabilidade; iii) aspectos físicos, químicos e microbiológicos e suas implicações; iv) controle da pureza para a água utilizada em caldeiras, e v) principais etapas e tratamento, nas Estações de Tratamento de Água (ETA).

b) Adesão bacteriana e os fatores que influenciam na formação de biofilmes. Foram obtidas informações sobre mecanismos de adesão, métodos visuais e não-visuais de avaliação e aspectos desejáveis e indesejáveis deste processo.

c) Princípios básicos e gerais do processo de higienização. Foram obtidas informações sobre i) composição dos resíduos de alimentos; ii) influência da natureza das superfícies no procedimento de higienização; iii) importância de cada etapa do procedimento geral; iv) agentes químicos detergentes e principais agentes químicos e físicos utilizados no processo de sanitização, seu mecanismo de ação e suas aplicações na UAN, e v) avaliação da eficiência antimicrobiana de sanitizantes químicos.

d) Principais doenças de origem alimentar, sua epidemiologia, microorganismos e alimentos envolvidos em surtos.

e) Legislação brasileira que trata da proteção da produção de alimentos.

f) Problemas típicos dos ambientes de processamento de uma UAN.

g) Equipamentos mais comuns de uma UAN, material de constituição, dificuldades do procedimento de higienização.

\section{Interface do sistema}

A interface do sistema foi construída com base na organização do conhecimento. Foram incluídos na equipe de trabalho, um programador, para criar o ambiente de desenvolvimento, e um programador visual, para produzir a identidade gráfica do sistema e a edição de vídeos, fotografias e animações. A ilustração textual, por meio de fotos, vídeos e animações, foi inserida para melhorar o entendimento do conteúdo. A produção destas mídias desenvolveu-se após a elaboração do conteúdo e, paralelamente, à construção da interface. Na produção de mídias dinâmicas foram produzidos os vídeos e as animações gráficas, e na produção de mídias estáticas, digitalizaram-se os textos e as imagens. Utilizou-se um computador Athlon XP 1,7Mhz, 256MB de memória RAM, monitor SVGA colorido, com placa de vídeo 3D RIVA TNT2.

\section{Desenvolvimento do aplicativo multimídia}

O aplicativo multimídia foi criado por meio do ambiente de desenvolvimento Borland Delphi, para sistemas com interface padrão Windows ${ }^{\circledR}$, que utiliza Object Pascal como linguagem de programação. Para a realização das animações, foi utilizado o Action Script, linguagem de programação do ambiente Macromedia Flash MX, por sua facilidade na manipulação de imagens vetoriais. Para o banco de dados, usou-se o Elevate Software DBISAN. Na preparação das imagens, empregaram-se os programas gráficos Adobe Photoshop e o Corel Draw. Na montagem dos textos, utilizou-se o Macromedia Dreamweaver MX, ferramenta que gera códigos HTML.

\section{Avaliação do sistema Clean Up}

A avaliação foi realizada disponibilizando uma cópia do Clean Up, sem o menu Ajuda. O teste de aceitação baseou-se na utilização de uma escala tipo Likert, de nove pontos, modificada com os atributos próprios de escala hedônica $(\text { Trochim })^{13}$. Desta maneira os atributos foram classificados nesta pesquisa pelos seguintes valores numéricos: extremamente bom, nota 9 ; muito bom, nota 8; moderadamente bom, nota 7; ligeiramente bom, nota 6 ; indiferente, nota 5; ligeiramente ruim, nota 4; moderadamente ruim, nota 3; muito ruim, nota 2 e extremamente ruim, nota 1. 
Foram selecionados 30 avaliadores entre estudantes de mestrado e de doutorado dos programas de pós-graduação em Ciência e Tecnologia de Alimentos, Microbiologia Agrícola e Ciência da Nutrição e Saúde, da Universidade Federal de Viçosa. As frases escolhidas para identificar os intervalos desta escala variaram de "extremamente bom", nota 9, quando o avaliador foi positivamente favorecido pela ferramenta a ele apresentada, até a nota 1,"extremamente ruim" quando o avaliador considerou que não foi favorecido pela ferramenta. Além disso, considerou-se como não-avaliado quando o avaliador não teve a disponibilidade da ferramenta ou por falta do resultado.

Ao avaliar a interface, obtiveram-se informações sobre a interatividade, a navegação pelos ambientes, o funcionamento dos ícones e a qualidade das mídias. Os avaliadores escolheram uma nota para as seguintes questões: apresentação das telas, estética e qualidade gráfica dos ambientes, cores e imagens na interface, facilidade de navegação pelos ambientes, legibilidade do texto. Ao avaliar o conteúdo, empenhou-se em coletar dados sobre a qualidade das informações escritas, qualidade das mídias (fotos e filmes), seqüência da apresentação do conteúdo, abordagem do assunto "higienização" no Clean Up, quantidade de informação disponível para o entendimento do assunto e adequação ao público-alvo. Outro objetivo foi coletar a opinião do usuário sobre cada módulo, após ter entrado em todos os ambientes e explorar o conteúdo pertinente.

A adequação do software também foi avaliada por meio de questões qualitativas complementares, investigando sobre os possíveis benefícios, obstáculos e mudanças significativas sugeridas pelo avaliador. Adicionalmente, sugestões e críticas foram solicitadas. Dos dados coletados das folhas de respostas preenchidas pelos avaliadores, foram calculadas a moda e os valores máximo e mínimo das notas para cada atributo julgado pelos avaliadores.

\section{RESULTADOS E DISCUSSÃ O}

O sistema multimídia consiste em cinco módulos, com informações interligadas, para facilitar a compreensão e para proporcionar rapidez no seu uso. Pela programação visual a partir do conteúdo, cada ambiente teve forma própria. O conceito de limpeza e higiene foi transmitido pelo design que remete aos ambientes de UAN, por exemplo, o uso de materiais de revestimentos cerâmicos, as superfícies com acabamento em aço inoxidável e a escolha de cores frias.

\section{Módulo 1: métodos de higienização}

Considerou-se relevante o detalhamento da higienização, que trata da efetiva remoção dos resíduos orgânicos e minerais da superfície pela correta utilização dos agentes de limpeza e de procedimentos adequados a cada superfície, com posterior sanitização. A execução das operações de higiene tem como base teórica os conhecimentos dos módulos Entendendo a Higiene, Limites Críticos e Ações Corretivas. Foram descritos informações e procedimentos para:

a) Manipuladores: foram propostas regras de higiene e de cuidados corporais, tais como, procedimento da higienização de mãos, e sugestões do uso correto para luvas, máscaras, uniformes e calçados.

b) Equipamentos e utensílios: foram agrupados 110 equipamentos e utensílios de acordo com o tipo de superfície, dificuldades de acesso à superfície a ser higienizada, tipo de sujeira aderida e métodos de higienização utilizados.

c) Alimentos: foram descritos os procedimentos para o controle microbiológico em função do pré-preparo, preparo, armazenamento após o preparo e manipulação.

d) Ambientes de processamento e ar dos setores de produção da UAN: detalham os procedimentos de limpeza das estruturas físicas, como teto, paredes, pisos com posterior e sanitização com emprego de agentes químicos. E, também, o procedimento para desinfecção do ar e do ambiente de processamento, com uso de 
pulverizador e sanitizantes químicos, para controle microbiológico.

\section{Módulo 2: limites críticos}

Neste módulo, estão descritos os limites críticos de segurança químicos, físicos e microbiológicos para o monitoramento durante o procedimento de higienização. Este módulo foi construído com os limites de segurança que deverão ser medidos e registrados com freqüência definida. O Clean Up fundamenta-se nas recomendações da American Public Health Association (APHA $)^{5}$ para proposição de limites críticos para o ar de ambientes de processamento, para superfícies de utensílios, equipamentos e manipuladores. No caso de alimentos, o sistema multimídia preconiza o uso da legislação da RDC 12, do Ministério da Saúde ${ }^{10}$.

\section{Módulo 3: monitoramento dos limites críticos}

Encontra-se descrito o procedimento de monitoramento, com enfoque em análises químicas, físicas e microbiológicas fundamentais ao controle do procedimento de higienização. Considerou-se que as análises físico-químicas e microbiológicas serão realizadas por terceiros e, por isso, é voltada a atenção para a coleta de amostras de: águas de abastecimento público e não tratadas, alimentos e ar do ambiente de processamento, pelas técnicas de sedimentação simples e impressão em ágar; superfícies; de equipamentos e utensílios higienizados, utilizando as técnicas do swab e da rinsagem das superfícies e, ainda, a técnica do swab para as mãos de manipuladores.

\section{Módulo 4: ação corretiva}

No Clean Up estão sugeridas ações corretivas aplicáveis a situações em que são observadas falhas na qualidade dos alimentos ou que podem ser detectadas a partir da lista de verificação das boas práticas de fabricação; dos registros de inspeção dos produtos; dos registros dos controles de temperatura; dos resultados da avaliação do procedimento de higiene pelo método ATP-bioluminescência ${ }^{14,15}$; e dos resultados das análises microbiológicas.

\section{Módulo 5: entendendo a higiene}

Este é o módulo mais abrangente do sistema e contém informações que dão apoio ao melhor entendimento dos módulos anteriores. Nele, encontram-se descrições sobre sujeiras e principais reações químicas envolvidas na remoção destas sejeiras, qualidade de água, superfícies que entram em contato com os alimentos, métodos de higienização, auxiliares de limpeza, detergentes, sanitizantes e adesão bacteriana (Figura 1).

\section{Módulos: itens de apoio}

Estes itens estão disponíveis em todos os ambientes do Clean Up, permitindo que o usuário tenha acesso direto, acionando o botão do mouse sobre o ícone correspondente à função desejada.

a) Identificação do usuário: ao inicializar o programa, é exibida ao usuário uma tela de identificação, na qual poderá ser cadastrado um novo usuário do programa. A partir desse cadastro, o usuário é identificado e é permitido que ele utilize os recursos do programa, como o Bloco de Notas.

b) Saiba Mais: o Clean Up disponibiliza para o usuário a seção intitulada "Saiba Mais", que oferece informações complementares para o processo de tomada de decisão.

c) Encontram-se disponíveis informações sobre: i) treinamento relativo à capacitação, desenvolvimento e motivação pessoal; ii) microbiota residente e transiente da pele humana; iii) influências ecológicas em produtos de higiene; iv) preparo da amostra para análise microbiológica da água e de alimentos; v) métodos de análises microbiológicas de água e de alimentos, e vi) avaliação da eficiência microbiológica de sanitizantes químicos associados ao procedimento de higienização. 

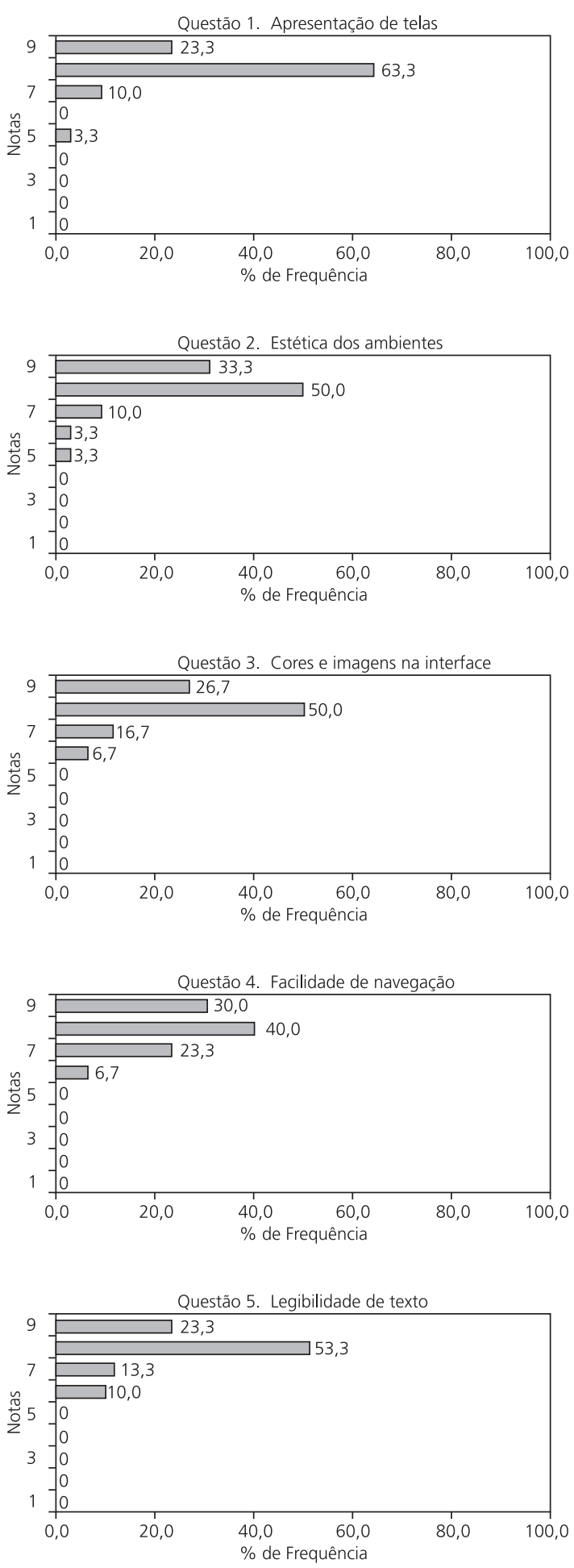

Figura 1. Porcentagens das freqüências das notas atribuídas às questões que avaliaram a interface $(n=30): 1)$ apresentação de telas; 2) estética e qualidade gráfica dos ambientes; 3) cores e imagens na interface; 4) facilidade de navegação pelos ambientes por usuários não-treinados; 5) legibilidade do texto. d) Glossário: o glossário elucida palavras e expressões utilizadas. São descritos 76 termos técnicos e científicos contidos no conteúdo do Clean Up. Na Figura 3, é mostrada a interação do usuário com o sistema.

e) Legislação brasileira: neste sub-item são mostradas, na íntegra, as legislações pertinentes ao sistema, com o objetivo de esclarecer ao usuário sobre normas e padrões vigentes $(\text { Brasil })^{6-12}$. São legislações obtidas em sites da Agência Nacional de Vigilância Sanitária (Anvisa), associada ao Ministério da Saúde e, também, no site do Ministério da Agricultura e do Abastecimento. Encontram-se no sistema portarias e resoluções que fundamentaram informações contidas no Clean Up, a Portaria $n^{\circ} 518$, de 25 de março de 2004 (Brasil) ${ }^{12}$; Resolução CONAMA $n^{\circ} 20$, de 18 de junho de 1986 (Brasil); ; Resolução de Diretoria Colegiada (RDC) n 12 - Alimentos (Brasil) ${ }^{10}$; Portaria $n^{\circ}$ 1.428/MS, de 26 de novembro de 1993 (Brasil);

f) Portaria SVS/MS n 326, de 30 de julho de 1997 (Brasil) $^{9}$; Resolução de Diretoria Colegiada (RDC) $n^{\circ} 275$, de 21 de outubro de 2002 (Brasil) ${ }^{11}$; Resolução Normativa $n^{\circ}$ 1/78, de 27 de novembro de 1978 (Brasil)6.

g) Blocos de notas: permite ao usuário fazer anotações, copiar referências e parte de textos. As informações poderão ser acessadas por qualquer programa de edição de textos fora do ambiente do sistema.

h) Ajuda: a ajuda é oferecida ao usuário indicando como o sistema funciona e identificando os ícones disponibilizados pelo Clean Up.

\section{Avaliação do sistema Clean Up}

Avaliação da interface: a interface possibilitou boa interação usuário e máquina, que se traduziu pelo uso do programa sem que houvesse necessidade de treinamento específico. O usuário acessa os ambientes com o auxílio de ícones, menus coloridos e imagens que sinalizam e marcam o caminho ao longo da interface. Todos os itens avaliados da interface foram classificados pelos 30 avaliadores como "muito bom". 


\section{Avaliação do conteúdo}

O conteúdo do Clean Up é uma ferramenta capaz de propiciar a aquisição de conhecimentos para a melhoria dos procedimentos de higiene e manipulação de alimentos, que foi o principal objetivo proposto neste trabalho. As questões receberam como moda as notas 8 e 9, classificando o conteúdo deste sistema como "muito bom" em qualidade e quantidade de informações e mídias e "extremamente bom", a abordagem do assunto higienização e a adequação do conteúdo ao público-alvo.

\section{Avaliação dos módulos}

Todos os módulos receberam com maior freqüência a nota 8, que corresponde à classificação "muito bom" pela escala Likert. Os módulos "Método de Higienização" e "Entendendo a Higiene" não apresentaram nota inferior a 7. Observa-se que o item de apoio
"Legislação" obteve como moda a nota 9, que corresponde à classificação "extremamente bom" . Porém, este item recebeu também uma nota 2 , que significa "muito ruim". A ocorrência desta nota foi devido à maneira de apresentação do módulo que, devido à extensão dos documentos relativos à legislação, preferiu-se a apresentação destes no ambiente do editor de textos. Essa mudança de ambiente causou impacto negativo no usuário, classificando-o como "muito ruim". O Bloco de Notas também foi classificado como "muito bom", com maior freqüência a nota 8 , mas, recebeu, também, a classificação de "ligeiramente ruim" por um avaliador e "indiferente" por outro. Verificou-se que na versão de avaliação do Clean Up, o Bloco de Notas não possui mobilidade na tela e, por isso, sobrepõe à do texto, dificultando a execução da atividade para a qual foi idealizado.

Os dados apresentados na Tabela 1 mostram a moda, o máximo e o mínimo das notas

Tabela 1. Moda, máximo e mínimo das notas atribuídas à interface, ao conteúdo e aos módulos do Clean Up, por 30 usuários que responderam a uma ficha de avaliação. Viçosa.

\begin{tabular}{|c|c|c|c|}
\hline Avaliação & Moda & Máximo & Mínimo \\
\hline \multicolumn{4}{|l|}{ Interface } \\
\hline 1) Apresentação das telas & 8 & 9 & 5 \\
\hline 2) Estética e qualidade gráfica dos ambientes & 8 & 9 & 5 \\
\hline 3) Cores e imagens na interface & 8 & 9 & 6 \\
\hline 4) Facilidade de navegação por usuários não-treinados & 8 & 9 & 6 \\
\hline 5) Legibilidade do texto & 8 & 9 & 6 \\
\hline \multicolumn{4}{|l|}{ Conteúdo } \\
\hline 6) Qualidade das informações escritas & 8 & 9 & 7 \\
\hline 7) Qualidade das mídias (fotos digitais e filmes) & 8 e 9 & 9 & 6 \\
\hline 8) Seqüência lógica da apresentação do conteúdo & 8 & 9 & 7 \\
\hline 9) Abordagem do assunto "higienização" no Clean Up & 9 & 9 & 7 \\
\hline 10) Quantidade de informação disponível para o entendimento do assunto & 8 e 9 & 9 & 6 \\
\hline 11) Adequação do conteúdo ao público-alvo & 9 & 9 & 5 \\
\hline \multicolumn{4}{|l|}{ Módulos } \\
\hline A) Métodos de higienização & 8 & 9 & 7 \\
\hline B) Limites críticos & 8 & 9 & 6 \\
\hline C) Monitoramento dos limites críticos & 8 & 9 & 4 \\
\hline D) Ações corretivas & 8 & 9 & 5 \\
\hline E) Entendendo a higiene & 8 e 9 & 9 & 7 \\
\hline F) Item de apoio: Saiba Mais & 8 & 9 & 6 \\
\hline G) Item de apoio: Glossário & 9 & 9 & 4 \\
\hline H) Item de apoio: Legislação & 9 & 9 & 2 \\
\hline I) Item de apoio: Bloco de Notas & 8 & 9 & 4 \\
\hline
\end{tabular}


atribuídas pelos avaliadores, para as questões que avaliaram a interface, o conteúdo e os módulos.

A Figura 1 é um exemplo da representação, na forma de gráficos, que mostra as porcentagens das freqüências das notas atribuídas às questões que avaliaram a interface.

\section{Avaliação qualitativa}

Os avaliadores desse estudo consideraram que o Clean Up poderá ser utilizado para treinamento e desenvolvimento pessoal, para maior estímulo no desenvolvimento de atividades de higienização, proporcionando interatividade entre gerência, equipe técnica e os manipuladores, com possibilidade de uso autônomo e realização de atividades cooperativas e colaborativas. Além das possibilidades citadas, os avaliadores sugeriram que o Clean Up proporciona ao usuário em uma UAN: independência de ação, retroalimentação do sistema de treinamento interno; alternativa de informação mais fácil e mais rápida; melhoria da qualidade de serviço e de produtos; otimização e correção das atividades de higienização.

Dentre os obstáculos para utilização, os avaliadores consideraram a falta de domínio no uso do computador e seus recursos, como o fator mais relevante. Mas, também consideraram o não entendimento do conteúdo como um possível obstáculo.

Alguns avaliadores também sugeriram que pode haver falta de interesse pelo assunto e ainda que o conteúdo seja monótono, cansativo. As principais mudanças sugeridas foram a inclusão de recursos e as modificações na forma de apresentação do conteúdo. Estão citadas algumas sugestões consideradas relevantes e que serão analisadas para possível implementação no Clean Up, para melhoria da satisfação do usuário: a) aumentar a área de apresentação do texto; b) aumentar a velocidade de apresentação da tela principal; c) incluir narrações para enriquecer a apresentação do conteúdo; d) substituir algumas fotos para melhorar a ilustração; e) incluir, na introdução, um resumo de cada módulo, apresentando os respectivos conteúdos; f) expandir o conteúdo do glossário e melhorar o sistema de busca; g) incluir novas fotos e filmes para melhorar o entendimento e proporcionar entretenimento durante a navegação; $h$ ) incluir mais remissões facilitando a busca pela informação por todo o sistema; i) resumir alguns itens do conteúdo, o que dispõe a informação na forma de tópicos.

\section{O N C L U S Ã O}

O sistema multimídia desenvolvido é uma ferramenta útil aos profissionais responsáveis pela qualidade dos alimentos produzidos em unidades de alimentação, principalmente no que se refere aos procedimentos de higienização de manipuladores, equipamentos e utensílios, ambientes de processamento auxiliando na obtenção de alimentos com boa qualidade nutricional, sensorial e microbiológica. A interface, o conteúdo e os módulos da ferramenta, que recebeu a denominação de Clean Up foram bem aceitos pelo grupo de avaliadores, de acordo com a pontuação obtida pelo sistema na Escala Likert. Algumas sugestões para a melhoria foram propostas pelos avaliadores e serão incorporadas ao Clean Up.

\section{A GRADECIMENTOS}

Ao CNPq, CAPES e FAPEMIG pelo apoio financeiro à pesquisa.

\section{REFER Ê NCIAS}

1. Associação Brasileira das Empresas de Refeições Coletivas - ABERC [Internet]. História, objetivos e mercado [Acesso 1 fev. 2003]. Disponível em: http: //www.aberc.com.br/ historia.htm

2. Fein SB, Lin CTJ, Levy AS. Foodborne illness: perceptions, experience, and preventive behaviors in the United States. J Food Protec. 1995; 58(12):1405-11. 
3. Lee WC, Lee MJ, Kim JS, Park SY. Foodborne illness outbreaks in Korea and Japan studied retrospectively. J Food Protec. 2001; 64(6): 899-902.

4. Fundação de Amparo à Pesquisa do Estado de Minas Gerais - FAPEMIG. Intoxicação alimentar. Minas Faz Ciência [periódico na Internet], 2002 ago 11 [Acesso 23 jan. 2003]. Disponível em: http:/ /revista.fapemig.br/11/intoxicação.html

5. Sveum WH, Moberg LJ, Rude RA, Frank JF. Microbiological monitoring of the food processing environment. In: Vanderzant C, Splittstoesser DF, editores. Compedium of methods for the microbiological examination of foods. 3rd. Washington (DC): APHA; 1992. p.51-71.

6. Brasil. Resolução Normativa $n^{\circ} 1$, de 25 de outubro de 1978. Aprova as normas a serem obedecidas pelos detergentes e seus congêneres. Conselho Nacional de Saúde. Ministério da Saúde. Diário Oficial da União; Poder Executivo, de 27 de novembro de 1978.

7. Brasil. (1986). Leis e Decretos, etc., Resolução CONAMA no 20, de 18 de junho de 1986. classificação das água doces, salobras e salinas do Território Nacional. Diário Oficial da República Federativa da União, Brasília, p.11356-11361, de 30 de julho de 1986.

8. Brasil. Portaria $n^{\circ} 1428$, de 26 de novembro de 1993. Regulamento Técnico para Inspeção Sanitária de Alimentos", as Diretrizes para o Estabelecimento de Boas Práticas de Produção e de Prestação de Serviços na Área de Alimentos e o Regulamento Técnico para o Estabelecimento de Padrão de Identidade e Qualidade (PIQ's) para Serviços e Produtos na Área de Alimentos. Ministério da Saúde. Diário Oficial da União; Poder Executivo, de 2 de dezembro de 1993.

9. Brasil. Portaria n 326, de 30 de julho de 1997. Aprova o Regulamento Técnico sobre Condições Higiênico-Sanitárias e de Boas Práticas de
Fabricação para Estabelecimentos Produtores/ Industrializadores de Alimentos. SVS/MS Ministério da Saúde. Secretaria de Vigilância Sanitária. Diário Oficial da União; Poder Executivo, de 1 de agosto de 1997.

10. Brasil. Resolução RDC $n^{\circ} 12$, de 02 de janeiro de 2001. Regulamento Técnico sobre padrões microbiológicos para alimentos. Anvisa - Agência Nacional de Vigilância Sanitária. Diário Oficial da União; Poder Executivo, de 10 de janeiro de 2001

11. BRASIL. Resolução RDC $n^{\circ} 275$, de 21 de outubro de 2002. Regulamento Técnico de Procedimentos Operacionais Padronizados aplicados aos Estabelecimentos Produtores/Industrializadores de Alimentos e a Lista de Verificação das Boas Práticas de Fabricação em Estabelecimentos Produtores/ Industrializadores de Alimentos. ANVISA - Agência Nacional de Vigilância Sanitária. Diário Oficial da União; Poder Executivo, de 6 de novembro de 2002.

12. Brasil. Portaria $n^{\circ}$ 518, de 25 de março de 2004. Estabelece os procedimentos e responsabilidades relativos ao controle e vigilância da qualidade da água para consumo humano e seu padrão de potabilidade, e dá outras providências. Ministério da Saúde. Diário Oficial da União; Poder Executivo, de 26 de março de 2004.

13. Trochim WMK. Likert scaling [acesso em 7 jul. 2003]. Disponível em: http://trochim.human. cornell.edu/ kb/scallic.htm

14. Baker JM, Griffiths MW, Collins-Thompson DL. Bacterial bioluminescence: applications in food microbiology. J Food Protec. 1992; 55(1):62-70.

15. Biotrace. Biotrace Xcel. Manual técnico. 2000.

Recebido em: 29/11/2004

Versão final reapresentada em: 30/5/2005 Aprovado em 29/6/2005 